\title{
Metastatic pulmonary calcification misdiagnosed as a fungal infection: A case report
}

\author{
ZHIXIN LIANG ${ }^{*}$, TIAN QIU*, ZHIGANG ZHAO, LIANG'AN CHEN and DANYANG SHE \\ Department of Respiration, Chinese PLA General Hospital, Beijing 100853, P.R. China
}

Received August 4, 2015; Accepted December 17, 2015

DOI: $10.3892 / \mathrm{mco} .2015 .723$

\begin{abstract}
Metastatic pulmonary calcification is a rare lesion, characterized by calcium salt depositing in normal lung tissue. The clinical profile of a case of metastatic pulmonary calcification following renal transplantation was described. A computed tomography scan of the chest revealed ground-glass opacities in bilateral lungs and a node exhibiting a halo in the right upper lobe, which were suspected aspergillus infection. Following examination and therapy, the results of lung biopsy revealed metastatic pulmonary calcification. Although metastatic pulmonary calcification was reported in renal failure patients previously, metastatic pulmonary calcification with cavity lesions has never, to the best of our knowledge, been previously reported. The aim of the present report was to improve the understanding of metastatic pulmonary calcification.
\end{abstract}

\section{Introduction}

Metastatic pulmonary calcification is a process performed in normal lung tissue with chronic renal disease. The patient was treated with immunosuppressive drugs following renal transplantation. The ground-glass opacities and nodular lesions, which are observed by a chest computed tomography (CT) scan may be signs of certain diseases, including cytomegalovirus pneumonia or pneumocystis carinii pneumonia. Cavity lesions with diffuse metastatic pulmonary calcification are rarely reported worldwide. In the present study, a case of metastatic pulmonary calcification following renal transplantation was reported in a patient whose CT scan of the chest revealed ground-glass opacities in bilateral lungs and cavity lesions in the upper right lung. Although aspergillus infection may be

Correspondence to: Dr Danyang She, Department of Respiration, Chinese PLA General Hospital, 28 Fuxing Road, Haidian, Beijing 100853, P.R. China

E-mail: shedanyang1@163.com

*Contributed equally

Key words: cavity lesions, metastatic pulmonary calcification, renal transplantation considered by chest $\mathrm{CT}$, metastatic pulmonary calcification must not be ignored in clinical diagnosis.

\section{Case report}

A 42-year-old man with renal failure received hemodialysis between November 2007 and 2008, prior to transplantation. The patient received renal transplantation in 2009. His maintenance immunotherapy consisted of mycophenolate (two capsules, twice/day); tacrolimus, (two capsules, twice/day) and methylprednisolone (40 mg daily). The patient improved following the treatment and was subsequently treated with methylprednisolone (4 mg/day). Lower extremity deep vein thrombosis was diagnosed by ultrasound in 2011 and the patient was treated with warfarin. On December 2012, the patient coughed white sputum and exhibited a fever at $39.6^{\circ} \mathrm{C}$. A CT scan of the chest revealed ground-glass opacities in bilateral lungs and nodular lesions in the right upper lobe (Fig. 1A). The patient was treated with voriconazole (400 mg/day), ceftriaxone sodium (1 g/day) and moxifloxacin (0.4 g/day).

In May 2013, the patient was readmitted for a fever, with blood in the sputum. All vital signs were stable. The entire body skin was slightly red with a scattered rash. Normal vesicular sounds were heard on auscultation without rales. Laboratory findings were as follows: Hemoglobin, $167 \mathrm{~g} / \mathrm{l}$; white blood cell (WBC) count, $16.00 \times 10^{9}$ cells/l; percentage of neutrophils, 0.859; C-reactive protein, $16.2 \mathrm{mg} / \mathrm{l}$ (normal range, $<5 \mathrm{mg} / \mathrm{l}$ ); procalcitonin, $0.85 \mathrm{ng} / \mathrm{ml}$ (normal range, $<0.5 \mathrm{ng} / \mathrm{ml}$ ); calcium, $2.41 \mathrm{mmol} / 1$ (normal range, 2.2-2.6 mmol/1); intact parathyroid hormone, $77.4 \mathrm{pg} / \mathrm{ml}$ (normal range, $15-65 \mathrm{pg} / \mathrm{ml}$ ). A CT scan of the chest revealed diffuse ground-glass opacities in bilateral lungs and cavity lesions within a nodule in the right upper lobe. The ground-glass opacities changed more than previously (Fig. 1B). The result of a lung biopsy in the right upper lobe demonstrated excessive thickening of the alveolar septa, alveolar epithelial hyperplasia, infiltration of inflammatory cells, multinucleated giant cells and calcification in the right lung tissue. Fiber polypoid tissues were observed in the alveolar space (Fig. 2). Immunohistochemical staining revealed the expression of cluster of differentiation (CD)68 (tissue cells positive), transcriptional intermediary factor-1 (epithelium positive), cytokeratin (epithelium positive). The result of staining with fiber polypoid tissues obtained from the lungs revealed negative acid fast staining and negative for Periodic 

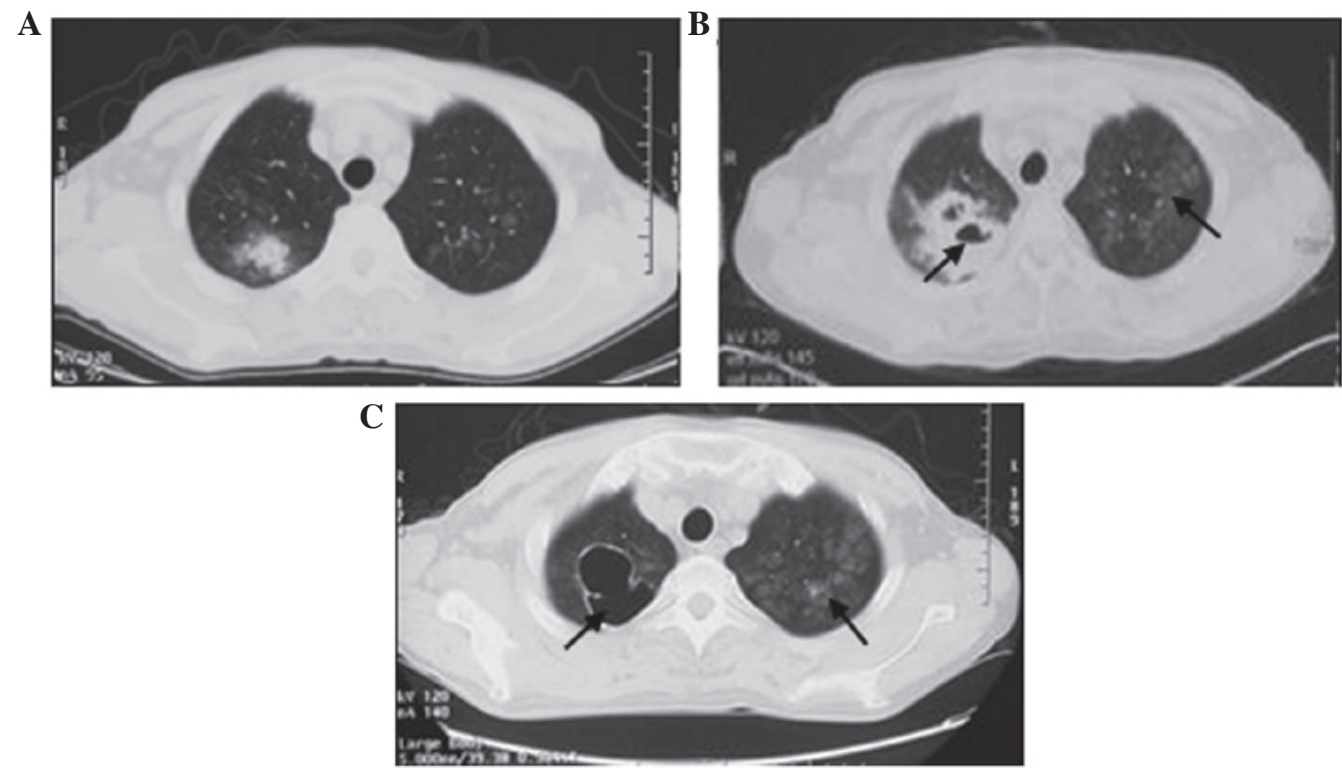

Figure 1. A computed tomography scan of the chest revealed (A) ground-glass opacities in bilateral lungs and a nodule exhibiting the halo sign in right upper lobe (10 December 2012), (B) diffuse ground-glass opacities in bilateral lungs and cavity lesions within a mass exhibiting the halo sign in right upper lobe (30 May 2013), and (C) diffuse ground-glass opacities in bilateral lungs and cavity lesions with thin cavity wall in right upper lobe. (6 August 2013).
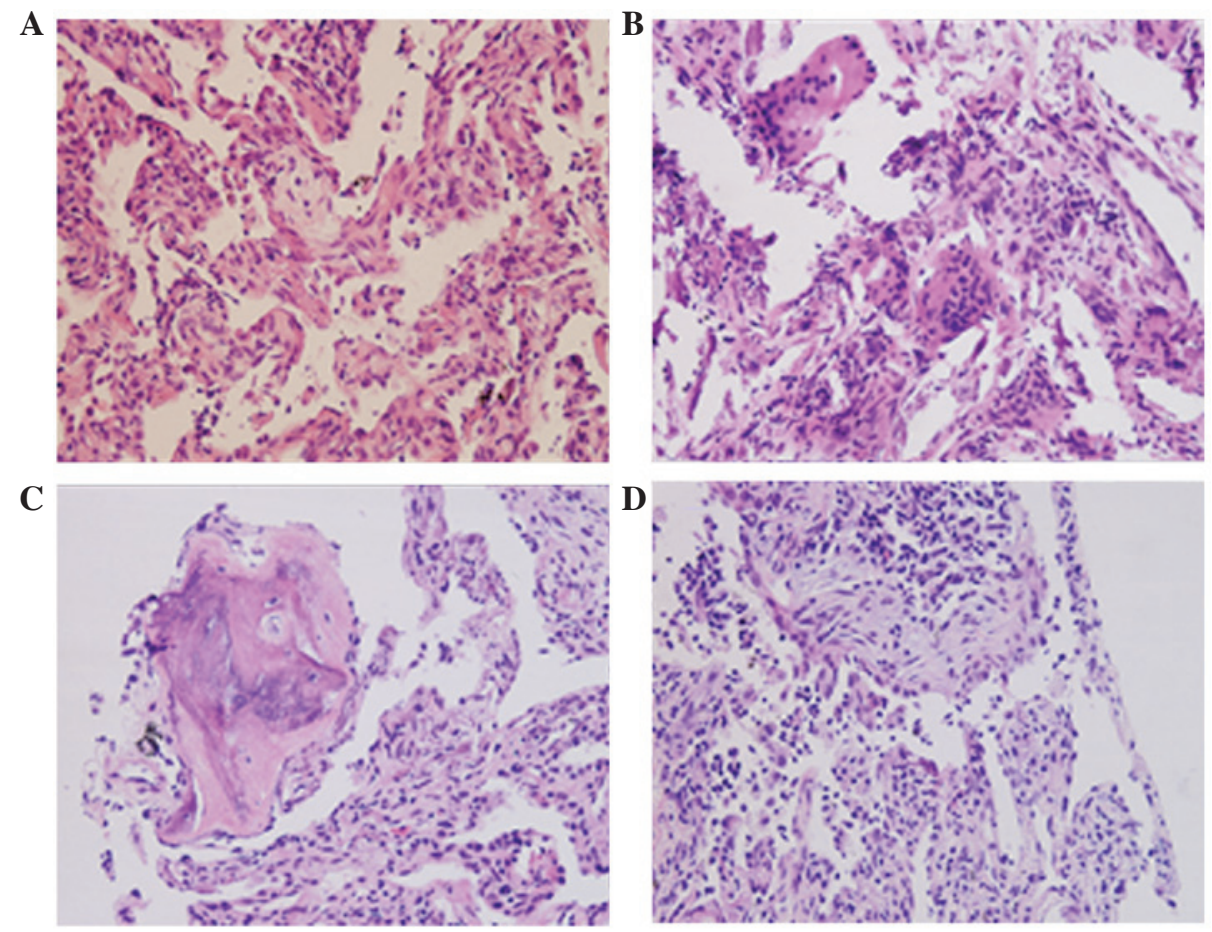

Figure 2. Pathology results in alveolar space. (A) Excessive thickening of the alveolar septa was observed. (B) Alveolar epithelial hyperplasia, infiltration of inflammatory cell and multinucleated giant cells were discovered in the tissue. (C) Calcification and ossification was observed. (D) Fiber polypoid tissues were observed in the alveolar space.

Acid-Schiff stain. No fungus or tubercle bacillus was observed by lung biopsy, and a lung tissue culture was negative.

According to clinical manifestation, medical history and a chest CT scan, aspergillus infection was initially considered in the patient. However, sustained treatment of voriconazole had little effect on the patient. Following a lung biopsy and sputum culture, pulmonary metastatic calcification was finally diagnosed in the patient. Anti-infective therapy was continued during his admission. The patient continued to take mycophenolate mofetil ( $250 \mathrm{mg}$ 1/day) and methylprednisolone (4 mg 1/day) until he was discharged. In August 2013, the imaging of pulmonary infection on CT scan of the chest was improved (Fig. 1C). The infection parameters and calcium-phosphate product were stable. The patient exhibited a significant clinical improvement and was discharged. The patient was in good clinical condition during the follow-up. He returned to our outpatient department for examinations every 4 months. Comparing new chest CT imaging with the 
images following the initial admission revealed that the lesions did not deteriorate.

\section{Discussion}

The present study searched previous cases of metastatic pulmonary calcification and eliminated those, which were irrelevant (1-12). The majority of the patients exhibited hypercalcemia and suffered from renal failure. Radiologically, metastatic pulmonary calcification predominantly appeared as diffuse small nodules with an unclear border, whose size ranged in diameter between 2 and $11 \mathrm{~mm}$. The majority of nodules were discovered in the upper lung area. The majority of patients survived during the follow-up period.

Metastatic pulmonary calcification is a complication characterized by calcium salt deposition. It belongs to visceral calcification (4) and may develop silently over years, and is often detected accidently. The pathogenesis is unclear; however, it is associated with calcium, phosphate, hemodialysis, hyperparathyroidism, renal failure, osteodystrophy, anticoagulants hypervitaminosis D and malignant tumor (13-16). Metastatic calcification may occur when calcium-phosphate products exceed $40 \mathrm{mg} / \mathrm{dl}^{2}(17,18)$. In autopsy studies, metastatic pulmonary calcification is observed in 60-80 percent of long-term hemodialysis patients, although it is rarely recognized during life (1). Calcium and phosphate were generally normal in the current patient during his admission. Long-term hemodialysis may lead to disorders of calcium and phosphate, which cause parathyroid hyperplasia. Additionally, parathormone must be secreted by it in order to balance electrolyte concentrations. It is difficult for calcium to be excreted with the urine in a patient with renal failure, and the calcium is deposited in the tissues. Low calcium in the plasma stimulates parathormone, which leads to increasing bone resorption. In addition, excessive secretion of parathormone is also caused by hyperparathyroidism (14). In the previous studies, the majority of the patients are associated with excessive secretion of parathormone, including renal failure and hyperparathyroidism (1-12). In the present case, lower extremity deep vein thrombosis was diagnosed by ultrasound in 2011 and the patient was treated with warfarin. Anticoagulants, particularly warfarin, can inhibit carboxylation of coagulation factors in the liver and peripheral carboxylation of matrix Gla protein, which results in a lack of vitamin $K_{1}$ and $K_{2}(8)$. Metastatic calcification may appear by this way. Certain malignant tumor types, particularly leukemia and multiple myeloma, can damage bone tissue, which releases calcium from the bone, contributing to hypercalcemia $(5,7,12)$.

A conventional chest radiograph seldom identifies calcification whose nodular opacities measure 2-12 $\mathrm{mm}$ in diameter (3). However, high-resolution computer tomography (HRCT) scanning and ${ }^{99 \mathrm{~m}}$ technetium-methylene diphosphate ( $\left.{ }^{99 \mathrm{~m}} \mathrm{Tc}-\mathrm{MDP}\right)$ bone scintigraphy are sensitive and specific (19). A CT scan of the chest following the patient being discharged home demonstrated that calcification exists in the tissue for a long duration. It is difficult for calcification to be absorbed completely when large numbers of calcium salts deposit in the tissue. In the previous cases, a chest CT scan of metastatic pulmonary calcification reveals diffuse, fluffy and ground-glass nodular opacities in the upper zones (1-12). The predilection of metastatic pulmonary calcification for the upper lung area may be due to the high ventilation/perfusion (V/Q) ratio in this region, creating low carbon dioxide and high oxygen levels (8). The V/Q ratio is high $(\sim 3.3)$ in the upper region and gradually reduces from apex to base $(\sim 0.63)$ in the lung. The high V/Q ratio results in decreased $\mathrm{PaCO}_{2}$ and increased $\mathrm{pH}$. Calcium salt deposition is associated with the relative alkalinity. As a result, metastatic pulmonary calcification usually occurs in the upper zones. Lung biopsy with pathological examination is the most accurate diagnosis for metastatic pulmonary calcification compared with HRCT or ${ }^{99 m}$ Tc-MDP, although they are sensitive. However, lung biopsy is more invasive compared with other examinations. Small quantities of calcification have little influence on patients, resulting in the probability of refusing a lung biopsy.

No appropriate treatment can be applied to metastatic pulmonary calcification. In previous cases, decreasing calcium in plasma was commonly used to treat calcification, including thyroparathyroidectomy and renal transplantation (1-12). In the present case, the calcium level was normal, and the patient underwent long-term immunotherapy. Aspergillus infection was as empirical diagnosis, according to the CT scan of the chest (Fig. 1A). Following biopsy in the right lung, metastatic pulmonary calcification was finally diagnosed. Notably, pulmonary function test results are usually normal in the early stage of calcification. With regard to metastatic pulmonary calcification, no abnormal symptoms can be observed in the early stage of small foci of calcification. The patient exhibited no symptoms and was not influenced by calcification. As the disease progresses, restrictive lung changes may develop with a decrease in vital capacity, diffusion capacity and hypoxemia. Prognosis depends on clinical conditions in patients. In addition, patients succumb to other diseases instead of calcification.

The present report expands metastatic pulmonary calcification with cavity lesions in the right upper lobe and in a patient following renal transplantation. The clinical symptoms of metastatic pulmonary calcification are not obvious. According to medical history and a CT scan of the chest (Fig. 1A), aspergillus infection was taken into consideration. However, lung biopsy and sputum culture demonstrated metastatic pulmonary calcification. Despite its rarity, metastatic pulmonary calcification must not be forgotten in clinical diagnosis when cavity lesions in the lungs are discovered in a patient. Regulating the balance of blood ions and improving immunity may reduce the incidence of calcification.

\section{References}

1. Hartman TE, Müller NL, Primack SL, Johkoh T, Takeuchi N, Ikezoe J and Swensen SJ: Metastatic pulmonary calcification in patients with hypercalcemia: Findings on chest radiographs and CT scans. AJR Am J Roentgenol 162: 799-802, 1994.

2. Brodeur FJ Jr and Kazerooni EA: Metastatic pulmonary calcification mimicking air-space disease. Technetium-99m-MDP SPECT imaging. Chest 106: 620-622, 1994.

3. Murris-Espin M, Lacassagne L, Didier A, Voigt JJ, Cisterne JM, Giron J, Durand D and Leophonte P: Metasatic pulmonary calcification after renal transplantation. Eur Respir J 10: 1925-1927, 1997.

4. Ullmer E, Borer H, Sandoz P, Mayr M, Dalquen P and Solèr M: Diffuse pulmonary nodular infiltrates in a renal transplant recipient. Metastatic pulmonary calcification. Chest 120: 1394-1398, 2001

5. Guermazi A, Espérou H, Selimi F and Gluckman E: Imaging of diffuse metastatic and dystrophic pulmonary calcification in children after haematopoietic stem cell transplantation. Br J Radiol 78: 708-713, 2005. 
6. Thurley PD, Duerden R, Roe S and Pointon K: Case report: Rapaidly progressive metastatic pulmonary calcification: Evolution of changes on CT. Br J Radiol 82: e155-e159, 2009.

7. Crippa C, Ferrari S, Drera M, Tardanico R, Ungari M, Facchetti F, Cancarini G and Rossi G: Pulmonary calciphylaxis and metastatic calcification with acute respiratory falure in multiple myeloma. J Clin Oncol 28: e133-e135, 2010.

8. Cadivid JC, Divietro ML, Torres EA, Fumo P and Eiger G: Warfarin-induced pulmonary metastatic calcification and calciphylaxis in a patient with end-stage renal disease. Chest 139: 1503-1506, 2011.

9. Mizushina Y, Bando M, Hosono T, Mato N, Nakaya T, Yamasawa H, Hironaka M, Tanaka A and Sugiyama Y: Arare case of asymptomatic diffuse pulmonary ossification detected during a routine health examination. Intern Med 51: 2923-2927, 2012.

10. Hochhegger B, Marchiori E, Soares Souza A Jr, Soares Souza L and Palermo L: MRI and CT findings of matastatic pulmonary calcification. Br J Radiol 85: e69-e72, 2012.

11. Yatera K, Kawanami T, Ishimoto H and Mukae H: Progressive metastatic pulmonary calcification after successful renal transplantation. Eur Respir Rev 22: 98-99, 2013.

12. Surani SR, Surani S, Khimani A and Varon J: Metastatic pulmonary calcification in multiple myeloma in a 45-year-old man. Case Rep Pulmonol 2013: 341872, 2013.
13. Goodamn WG, Goldin J, Kuizon BD, Yoon C, Gales B, Sider D, Wang Y, Chung J, Emerick A, Greaser L, et al: Coronary-artery calcification in young adults with end-stage renal disease who are undergoing dialysis. N Engl J Med 342: 1478-1483, 2000.

14. Ando T, Mochizuki Y, Iwata T, Nishikido M, Shimazaki T, Furumoto A, Minami S, Kinoshita N and Kawakami A: Aggressive pilmonary calcification developed after living donor kidney transplantation in a patient with primary hyperparathyroidism. Transplant Proc 45: 2825-2830, 2013.

15. Jevtic V: Imaging of renal osteodystrophy. Eur J Radiol 46: 85-95, 2003.

16. Hansen D, Rasmussen K, Rasmussen LM, Bruunsgaard H and Brandi L: The influence of vitamin D analogs on calcification modulators, $\mathrm{N}$-terminal pro-B-type natriuretic peptide and inflammatory markers in hemodialysis patients: A randomized crossover study. BMC Nephrol 15: 130, 2014.

17. Ketteler M, Rothe H, Krüger T, Biggar PH and Schlieper G: Mechanisms and treatment of extraosseous calcification in chronic kidney disease. Nat Rev Nephrol 7: 509-516, 2011.

18. Tristano AG: Metastatic calcification of the hand in a patient undergoing hemodialysis. Am J Med 116: 572-573, 2004.

19. Chan ED, Morales DV, Welsh CH, McDermott MT and Schwarz MI: Calcium dsposition with or without bone formation in the lung. Am J Respir Crit Care Med 165: 1654-1669, 2002. 